\title{
Perspectives on Adolescent Pregnancy Prevention Strategies in the United States: Looking Back, Looking Forward
}

This article was published in the following Dove Press journal: Adolescent Health, Medicine and Therapeutics

\author{
Claire D Brindis (iD) \\ Martha J Decker (D) ${ }^{1,2}$ \\ Abigail Gutmann-Gonzalez $\mathbb{D}^{2}$ \\ Nancy F Berglas $\mathbb{D}^{1-3}$
}

'Philip R. Lee Institute for Health Policy Studies, Adolescent and Young Adult Health National Resource Center, Bixby Center for Global Reproductive Health, University of California, San Francisco, San Francisco, CA 94II8, USA; ${ }^{2}$ Philip R. Lee Institute for Health Policy Studies, University of California, San Francisco, San Francisco, CA 94II8, USA; ${ }^{3}$ Bixby Center for Global Reproductive Health, University of California, San Francisco, Oakland, CA 946/2, USA
Correspondence: Claire D Brindis Philip R. Lee Institute for Health Policy Studies, Adolescent and Young Adult Health National Resource Center, Bixby Center for Global Reproductive Health, University of California, San Francisco, 3333 California Street, Suite 265, San Francisco, CA 94II8, USA

Tel +I (4I5) 5I7-452I

Email claire.brindis@ucsf.edu

\begin{abstract}
Attempts to solve the "problem of adolescent pregnancy" have long been a focus of national, state, and local efforts in the United States. This review article summarizes trends and strategies around adolescent pregnancy prevention, provides lessons learned and best practices, and presents ideas for future directions. Over the past decades, a wide variety of policy and programmatic interventions have been implemented - including educational efforts, clinical health services, and community-wide coalitions - accompanied by a growing consensus regarding viable solutions. While notable reductions in adolescent pregnancy and childbearing have occurred across all sociodemographic groups, racial/ethnic, geographic, and socioeconomic disparities persist. Many adolescents who most need sexual health information and services are underserved by current programs and policies. A growing understanding of the role of social determinants of health, the impacts of structural racism, and the need for equity and inclusion must inform the next set of interventions and societal commitments to not only ameliorate the occurrence of unintended adolescent pregnancy but also foster healthy adolescent development. Recommendations for future efforts include improving the content, quality, and sustainability of education programs; actively engaging youth in the design of policies, programs, and clinical services; using technology thoughtfully to improve health literacy; expanding access to services through telehealth and other delivery options; and designing programs and policies that recognize and address structural racism, health equity, and inclusion.
\end{abstract}

Keywords: pregnancy in adolescence, sex education, reproductive health services, United States

\section{Introduction}

American society has long exhibited tremendous discomfort regarding adolescent sexuality, the provision and content of sexual health education, adolescents' access to confidential contraceptive services, and the role that government policy and funding should play in influencing and supporting personal decisions that have societal consequences. Against this backdrop, attempts to solve the "problem of adolescent pregnancy" and its health, economic, and educational impacts on the adolescent, her child, family, and society, have been a focus of policy and programmatic efforts for decades. More recently, reframing efforts have attempted to shift viewing adolescence from a deficit model to one that recognizes the importance of approaching this developmental period and adolescent pregnancy prevention through a strengths-based, positive youth development lens. ${ }^{1}$ 
Woven through the DNA of generations of adolescent pregnancy prevention strategies remains the residual controversy over whose responsibility it is to intervene and what are the best approaches to do so. Encouragingly, a wide variety of programmatic and policy-level interventions at the national, state, and local level have been implemented, accompanied by a growing consensus regarding viable solutions. While notable reductions in adolescent pregnancy and childbearing have occurred across all sociodemographic groups, racial/ethnic, geographic, and socioeconomic disparities persist. Many adolescents in greatest need of sexual health information and services remain underserved by current programs and policies. ${ }^{2}$ A growing understanding of the role of social determinants of health, the impacts of structural and interpersonal racism, and the need for equity and inclusion must inform the next set of interventions and societal commitments to not only ameliorate the occurrence of unintended adolescent pregnancy but also foster healthy adolescent development.

Over the past five decades, our understanding of the myriad factors that influence adolescent pregnancy has evolved, and tremendous strides have made in assessing the types of policies and programs that prevent unintended pregnancies and support adolescent sexual health. To understand where we are now and plan for the future, this paper provides a historical review of trends in adolescent births in the United States and pregnancy prevention strategies. Specifically, it reviews the evolution of efforts aimed at increasing the availability of sexual health education, clinical services, and the establishment of national, state, and local coalitions aimed at the prevention of adolescent pregnancy. Prior research has assessed specific aspects of adolescent pregnancy prevention efforts, including sexual health education and clinic interventions. ${ }^{3-5}$ The aim of this paper is to provide a retrospective review of the field of adolescent pregnancy, to highlight lessons learned in each area, and to present ideas for future directions for the field.

\section{Trends in Adolescent Childbearing Historical Perspectives}

Adolescent childbearing is not a new American phenomenon; in 1960, the adolescent birth rate (ABR) was 89 births per 1000 young women aged 15-19. The ABR has since declined to 17.4 births per 1000 in 2018, a remarkable $72 \%$ decrease since $1991 .^{6}$ The dramatic declines in the rates of adolescent pregnancy and births over the past 30 years is touted as one of the most successful public health wins. ${ }^{7}$

An important factor in decreasing rates of adolescent pregnancy are changes in social norms, with many youth delaying the initiation of sexual activity. The percentage of youth aged 15-19 reporting having ever had sex has declined significantly over the past 25 years (1988 to 2013), by 14\% for females and $22 \%$ for males. ${ }^{8}$ Many are opting to reduce their overall number of sexual partners and to use contraceptive methods more consistently. ${ }^{9,10}$ In 2015-2017, most females (78\%) and males (89\%) who had sexual intercourse before age 20 used a contraceptive method the first time they had sex. In addition, a growing percentage of adolescents are using highly effective, long-acting, reversible contraception (LARCs). ${ }^{2}$

Despite these improvements, significant disparities remain in the incidence of adolescent pregnancy and childbearing by geographic area, race/ethnicity, economic level, and other segments of the adolescent population. ${ }^{11}$ Disparities regarding pregnancies are much higher among the most vulnerable populations, including youth who are homeless, living in foster care, or involved with the juvenile justice system. ${ }^{12,13}$

\section{Lessons Learned}

Dramatic decreases have occurred in adolescent pregnancy and childbearing, reflecting changes in social norms and greater accessibility and use of contraception. First, the availability of different and additional methods of contraception, including LARCs and injections, have provided additional options for adolescents. However, increasing rates of sexually transmitted infections among youth point to the importance of finding additional ways to support consistent condom use. Different policies and funding may also impact access to care, for example, whether a state has policies regarding adolescents' ability to access confidential care.

Second, disparities in the rates of adolescent pregnancy and childbearing often reflect broader societal disparities in access and other social determinants of health. Community-level factors such as educational attainment, poverty, and structural and interpersonal racism play an important role in $\mathrm{ABR}$ disparities. Under-resourced schools are detrimental for adolescents' sexual health knowledge, and low education attainment is associated with a higher likelihood of pregnancy. ${ }^{14-16}$ Lack of recreational opportunities and cost-barriers to recreational activities may result in less supervised time out of school and 
thus more opportunities for sexual activity and risk behaviors for adolescents. ${ }^{15}$ Many adolescents also face concurrent challenges and inequities that may contribute to their increased risk of negative sexual health outcomes, such as substance abuse, which often begins during adolescence. ${ }^{17,18}$

Third, cultural and religious norms in some communities may act as barriers for youth to learn about and receive sexual health services. ${ }^{19}$ Many first generation immigrants and families face challenges accessing services that are linguistically and culturally appropriate. ${ }^{20}$ They also may face additional barriers related to public policies, such as changes in immigration laws, concerns about deportation, and new public charge requirements, which result in delaying or inhibiting needed care. ${ }^{21}$ Culturallybased childbearing norms, such as conservative attitudes about sexuality, contraceptive use and traditional gender norms, may also contribute to disparities in adolescent childbearing. ${ }^{22,23}$

Fourth, while disaggregated data, such as by race/ethnicity, age, and rural/urban areas, help policymakers, program directors, and health care providers develop targeted strategies, additional data are needed to capture the intersection and complexities within populations. For example, youth in urban areas may also be involved in the foster care system, while other youth who are homeless may be living in rural areas and previously involved with the juvenile justice system. Such nuanced data are important to understand the diversity of lived experiences among adolescents and create tailored interventions that resonate with their audience. Otherwise, reducing or ameliorating sexual health disparity gaps will remain elusive goals.

\section{School- and Community-Based Educational Approaches Historical Perspectives}

Initial adolescent pregnancy prevention efforts began in the 1970s and 1980s with relatively simple and unidimensional interventions, primarily educational. The continued high rates of adolescent childbearing in the early 1990s served as a mobilizing call for further action. ${ }^{24}$ What had changed most visibly from previous generations was the increase in sexual activity and childbearing outside of marriage, and as a consequence, an increase in adolescent single parenthood. ${ }^{25}$ Growing concerns reflected reports of potential health, education, economic, and social consequences resulting from adolescent childbearing.
Early efforts to address adolescent pregnancy focused primarily on educational interventions, eventually evolving to recognize the need for a more comprehensive set of sustained responses. Initially, sexual health education in schools aimed to close information and knowledge gaps, particularly around anatomy and puberty, and often focused on the negative consequences of pregnancy and sexually transmitted infections. Within these education efforts, tension has long existed between approaches that stress the importance of delaying sexual activity until marriage to those that argue for more comprehensive approaches that provide information about both abstinence and contraception. ${ }^{4}$ Though knowledge remains an important building block, eventually professionals recognized that efforts to develop skills, change norms, and improve self-efficacy were also needed. ${ }^{26}$

Since the 1990s, new generations of programs have focused on developing multi-pronged education efforts that included sexual health knowledge, information on youthfriendly clinics and community resources, and skill-building through role plays and games. For example, curricula such as Making Proud Choices have helped young people develop skills in communicating with their partners regarding their comfort level in engaging in sexual activity. ${ }^{27}$ The field also benefitted from the concurrent movement to reduce the risk of HIV/AIDS, resulting in integrated strategies and curricula to address both pregnancy and sexually transmitted infections. ${ }^{28}$ Other emerging approaches focused on positive youth development and actively engaging young people in community settings to develop life skills. Examples of programs going beyond sexual health education include the Teen Outreach Program that incorporated community service learning experiences and the Children's Aid Society's Carrera program that offered job training opportunities, mentoring, and scholarships to attend college among its comprehensive services. ${ }^{29,30}$

Beginning in the 1990s, the pressing need to know "what works" and for whom led to a major movement in funding evaluations to assess program effects on adolescent behaviors and sexual health outcomes. Through these and many other efforts, a body of evidence emerged regarding educational interventions that both delay sexual activity and increase contraceptive use among those who were sexually active. Dr. Doug Kirby made a significant contribution when he first assessed the key cross-cutting components of these successful education programs. ${ }^{31}$ These findings were followed by other important syntheses and systematic reviews of successful programs by governmental agencies, independent research organizations, and 
advocacy groups. ${ }^{32,33}$ With these compilations, and similar ones focused HIV/AIDS education, many funders began requiring grantees to select an evidence-based intervention and gave guidance to schools and community-based organizations looking for tested strategies to implement in their communities.

More recently, the focus on implementing evidencebased interventions with fidelity has highlighted the importance of adaptation to fit the local context and the recognition of the need for ongoing innovation in content and pedagogy, while also following the tested program model. ${ }^{34}$ Additionally, recent sexual health education innovations have incorporated technology, including mobile apps, online classes, and websites. ${ }^{35,36}$ While these interventions have shown promise, their effectiveness requires further research.

\section{Lessons Learned}

Over time, several lessons have emerged regarding educational approaches to adolescent pregnancy prevention. First, the complexities of adolescent pregnancy's root causes, such as poverty and limited educational opportunities, require that interventions go beyond the traditional sexual health education approaches that had addressed only abstinence and/or contraception. This includes developing life skills such as fostering healthy relationships, managing stress, and improving communication. Interventions may also help prepare young people for adulthood through budgeting, applying for financial aid, and developing job interview skills. ${ }^{37}$

Secondly, recognizing adolescence as a key developmental period in which young people should be supported in building personal strengths, skillsets, and positive relationships has helped shape the types of interventions available in schools and community settings. ${ }^{1}$ This requires mobilizing networks of family members, schools, and youth-serving organizations to support positive youth development and provide alternatives to early childbearing by promoting academic success and expanding employment options.

Third, the political arena continues to shape prevention interventions, with the pendulum shifting with federal and state administrations that support abstinence-only education vs comprehensive, evidence-based sexual health education approaches. In addition, some communities and politicians continue to resist offering sexual health education in schools, believing that education should focus on academic subjects or that such discussions should only be addressed in the home.

Fourth, while more comprehensive models have been developed, too often their extra investment costs are seen as prohibitive, although such investments would have increased traction if measuring longer-term outcomes. ${ }^{38}$ The unique needs of different adolescent populations, such as youth leaving the foster care system, requires thoughtful program adaptation and innovation, as well as longer and multi-pronged sustainable programs.

Fifth, while federal funding, and in some cases, state and local funding, has contributed to reaching more adolescents, many communities remain underserved. Even among higher resourced communities, many adolescents are not being reached with existing programs. This is particularly challenging for communities that are unable to pursue program sustainability once funding ends as public grant funds are difficult to replace.

Sixth, while some funding requires replication of an evidence-based intervention, program providers often face challenges in implementing these programs in new settings. ${ }^{34}$ Additional support is needed to balance fidelity to key components that contributed to the intervention's original success with adaptations to meet the needs of specific populations and be culturally responsive. ${ }^{39}$ Programs must continue to focus on the quality and capacity of health educators who are directly interacting with youth, whether based in schools or community-based organizations. Their comfort level with the content being taught, and ability to treat adolescents in a respectful and inclusive manner, maximizes the opportunity for learners to gain new knowledge and skills.

\section{Clinical Services for Adolescents Historical Perspectives}

Improving access to free or subsidized confidential sexual health care for adolescents, supported through the federal Title X program, Medicaid, and the Affordable Care Act, represents another key adolescent pregnancy prevention strategy. More recently, the availability and subsidy of LARC methods have also contributed to increasing the effectiveness of methods used by adolescents. ${ }^{40}$

Although these funding programs have increased the availability of contraceptive services, significant barriers remain for many adolescents to access them. Structural barriers, such as transportation, clinic location, and scheduling, may limit adolescents' ability to receive services in 
a timely manner. ${ }^{41}$ Adolescents often are concerned about stigma and confidentiality, particularly that their parents may learn they are seeking care. For youth living in rural settings, as well as sexual minority youth, these fears may be even more pronounced. ${ }^{19,42}$ Males in particular often feel unwelcome in clinic settings. ${ }^{43}$

Clinics and programs need to address and respond to the barriers that adolescents face when seeking sexual health services. Some clinics have implemented special community outreach and education strategies to help young people access care. Clinics have also trained youth to serve as peer educators and outreach workers. In one study, peer providers within the clinic who provided all non-clinical care components of the visit were shown to be particularly effective for Latinx patients and those patients whose own mothers had been adolescent mothers. ${ }^{44}$ Strategies to create more youth-friendly clinics include developing protocols to ensure privacy and confidentiality, having youth-only clinic hours, and training clinic staff to be non-judgmental and respectful. ${ }^{45,46}$ More recently, the use of technology has also expanded ways to reach adolescents and encourage them to seek care.

Basing clinics in easily accessible locations, including the use of school-based clinics and mobile vans, has been shown to be an effective way of enhancing adolescent access to services, as well as improving adolescent satisfaction with and continued use of contraceptive methods. ${ }^{47}$ School-based clinics in particular help facilitate service use by being located where adolescents spend much of their time. ${ }^{48}$

More recently, some health providers and advocates have focused on increasing the numbers of adolescents who receive contraceptive services through sources other than traditional clinic visits. Condoms have been available through pharmacies and grocery stores for decades, although many adolescents continue to experience stigma, embarrassment, and cost concerns when accessing them. Over-the-counter birth control and the availability of receiving birth control by mail could reduce many common barriers to care. ${ }^{49,50}$ As a result of the COVID-19 pandemic, some health clinics have converted or expanded their services to telehealth, though the acceptability and efficacy of this strategy remains uncertain for the general adolescent population. $^{51}$

\section{Lessons Learned}

First, while clinical sexual health services exist across the country, adolescents continue to face major challenges in accessing care. Clinics and providers are often not youth friendly. Many youth face additional barriers, especially those living in rural communities where social norms may continue to make adolescents fearful of seeking care or where confidential services may not be available.

Secondly, though most adolescents receive some form of sexual health education in school, few receive concrete information regarding the availability of confidential sexual health services within their own community. The lack of a clear bridge between classroom education and clinics contributes to adolescents' ongoing sense of stigma, embarrassment, and fear regarding accessing services.

Third, greater efforts are needed to engage parents and other adult caregivers in support their children's use of services, while also maintaining individual adolescents' preferences for the confidentiality of services. Clinics and health educators need to consider the kinds of educational messages, workshops, and other community outreach strategies needed to increase support among adults for adolescents accessing care. Developing family communication skills, clarifying what clinic services entail, and emphasizing the importance of adolescents' acquiring skills to successfully navigate health-seeking behavior are all important topics to cover.

Fourth, political controversy regarding provider counseling, as reflected in recent Title $\mathrm{X}$ regulations that preclude their providers from referring pregnant patients to abortion services, has resulted in large number of clinics dropping out of the program. ${ }^{52}$ The largest of these networks is Planned Parenthood, which traditionally has served as an entry clinic for many adolescents.

\section{Building Coalitions at the National, State and Local Level Historical Perspectives}

In addition to efforts to improve and expand education programs and clinical services, public health professionals, policymakers, foundation representatives, and advocates have mobilized initiatives at the local, state, and national level by establishing coalitions focused on reducing rates of adolescent pregnancy and promoting sexual health education policies.

State adolescent pregnancy prevention coalitions grew fairly rapidly in the late 1990s, from 32 state coalitions in 1995 to 41 coalitions in states and the District of Columbia in $2001 .^{53}$ Often established with the commitment of governors, these resulted in bringing the governmental, non- 
governmental, and private sectors together to marshal new and existing funding resources in a more systematic way. States used their coalitions to develop plans that brought education, health, and employers together, as well as to promote changes in state policies, such as requiring comprehensive sexual health education in public schools. ${ }^{54}$ For example, in 1988, California convened key stakeholders and established a comprehensive state strategic plan on Teenage Pregnancy Prevention. ${ }^{55}$

In addition, multiple efforts have been made by the National Campaign to Prevent Teen and Unplanned Pregnancy (now known as Power to Decide) and state coalitions to reach and educate the public by using a variety of educational and media platforms, including news articles highlighting the extent and impact of adolescent pregnancy on lifetime outcomes. Editorials, opinion pieces, and major articles in mainstream magazines were published. Scripts and storylines for television shows including an MTV series incorporated adolescent pregnancy messages, encouraging young people to delay having sex or to use contraception.

A number of initiatives at the federal level examined the potential role of community coalitions and partnerships in reducing the incidence of adolescent pregnancy. In 1995, one of the first national, multi-site, comprehensive efforts to adopt a community-level approach to adolescent pregnancy was established: The Centers for Disease Control and Prevention (CDC) funded the Community Coalition Partnership Program in 13 communities across the country to enhance their capacity to reduce adolescent pregnancy by building partnerships, mobilizing community resources, and increasing the number and quality of programs involved. ${ }^{56}$ Evaluation results showed that while there was success in attracting new groups to work together on the issue, greater resources were needed to solidify the partnerships and make an impact. ${ }^{57}$

A second federal attempt to build community coalitions established a national demonstration project integrating services, programs, and strategies through communitywide initiatives. Supported through a special partnership between the CDC and Office of Adolescent Health, this project helped to ascertain whether comprehensive and community-wide approaches would help to reduce adolescent pregnancy. It combined a number of strategies to improve educational interventions and access to clinical care, including providing guidelines for selecting the most appropriate educational and clinical evidence-based practices. The program demonstrated the importance of incorporating quality improvement strategies for ongoing service improvements, as well as partnerships to address socio-economic and other determinants of health that contribute to adolescent childbearing.

In recent years, many of these coalitions have evolved from a narrow goal of reducing adolescent pregnancy to a broader vision of improving adolescent sexual health. This superseded some of the shame-based, abstinence-only campaigns and gave way to more nuanced portrayals of adolescents and the need for a focus on health beyond preventing pregnancy. A relatively recent renaming of the National Campaign to Prevent Teen and Unintended Pregnancy to "Power to Decide" reflects an important evolution acknowledging the rights of individuals to choose their own reproductive pathways.

\section{Lessons Learned}

First, the mobilization of policymakers and different sectors, including education, health, and economic development, regarding the issue of adolescent pregnancy helped to increase visibility regarding the importance of adolescent pregnancy prevention, assuring a greater sense of urgency and shared responsibility for solutions that went beyond the family.

Secondly, in some states, complementary governmentled initiatives were brought together to increase coordination across shared agendas. For example, in California, the state Department of Education and the Department of Public Health worked together on an adolescent pregnancy prevention initiative that aimed to both improve educational outcomes, as well as reduce unintended pregnancy among students, a major cause of school dropout. ${ }^{58}$

Third, the synergy of working at the federal, state, and local level through multi-pronged approaches helped to further extend the impact of any one effort, reinforcing messages and creating a philosophy of rowing together in the same direction, even when there was tension on which approach(es) might be best. The momentum and consistent investments helped to respond to new cohorts entering their adolescent years, and also reflected a growing understanding of the complexity of adolescent pregnancy as an issue that could not be readily solved within a limited time period.

Fourth, creative solutions, including developing youth councils and incorporating youth voices in program design, community education outreach strategies, and website development, became a stronger and recognized program component. 
Finally, a number of coalitions adapted over time to expand beyond a focus on adolescent pregnancy to other concurrent youth issues, such as substance use, mental health, and economic development. These coalitions' ability to pivot and respond in nimble ways helped to sustain their structures, while also responding to many issues that youth face.

\section{Implications and Future Steps}

The field of adolescent pregnancy prevention has undergone major growth and iterations through generations of responses to the complexities of the issue. In thinking about future directions, it is critical to build upon this history and continue to enhance our strategies. We highlight the following five recommendations in an effort to build future approaches that are tailored to adolescents' needs, incorporate their perspectives, are respectful of their capacities for growth and change, reflect their lived experiences, and are driven by principles of equity and inclusion.

\section{Recommendation I: Improve the Content, Quality, and Sustainability of Educational Programs}

At the core, there is a need to continue to improve our approaches to delivering vital information that will help assure that adolescents will be able to navigate their transition to young adulthood. Traditionally, delivering sexual health information has occurred through time- and content-limited educational interventions. The content may have provided information on contraceptive methods, but, for the most part, bridges to accessing health care services have been relatively weak.

Variability in the content, quantity, and quality of sexual health education programs contributes to an uneven landscape among adolescents. Furthermore, sexual health education traditionally has been offered just a few times during middle and high school years, with an implication that the information will not need further repetition, reinforcement, or refinement. However, during the adolescent years, complex family dynamics, relationships with peers and partners, and exposures to varying pressures lead to developmentally distinct needs and questions based upon experiences and opportunities. For example, hearing information on where to access contraceptive services has greater relevance when one contemplates or begins sexual activity. Adolescents need developmentally appropriate repetition and reinforcement in high school and in non-school settings because they are regularly encountering new situations and have questions that deserve to be answered.

Future development of sexual health education programs must also be more responsive to and inclusive of the evolving understanding of gender and sexual orientation spectrums. Programs must also be more culturally responsive and inclusive, reflecting the realities of different communities' experiences, norms, and histories. These efforts need to emphasize sexual health not only from a prevention standpoint, but also from a rights-based framework that centers healthy relationships, sexual pleasure, open communication, and consent.

We have encountered challenges in achieving similar health behavior outcomes when replicating rigorously tested programs, as well as challenges in sustaining financial support for programs once initial funding ends. With the growing interest in the role and acceptability of technology among adolescents, the next generations of efforts may benefit from hybrid models, where text or other platforms respond to the changing context of young people's lives. Many such models are being developed and tested now, and hold promise to be a component of the next generations of educational approaches.

\section{Recommendation 2: Actively Engage Youth in the Design of Policies, Programs, and Clinical Services}

Over the past several decades, there has been an increased focus on incorporating youth perspectives in the design of programs and policies, such as identifying barriers to care or developing clinic outreach strategies. Greater efforts are needed to ensure that youth-centered design is prioritized and incorporated in program planning and that adolescents are recognized and supported in their role as program leaders. This will be especially important as programs strive to reach populations who are marginalized from schools or traditional health care delivery settings.

Engaging youth as full and authentic partners is key in assuring that programs remain fresh, relevant to their targeted audiences, and offer the quality of care that is needed, while also furthering efforts to ameliorate disparities. Key to these youth-centered approaches are the skills, competencies, confidence, and connections that develop among youth who are engaged in meaningful ways. 


\section{Recommendation 3: Use Technology} Thoughtfully to Improve Health Literacy

Technology and social media play increasingly important roles in the lives of adolescents and shape their sense of agency, their identities, the types of information they receive, and their ability to assess the merit of information. While many sexual health clinics and education programs had previously adopted the use of technology, including websites, apps, and social media, many have had to adapt further in response to the COVID-19 pandemic. Decisions regarding when it will be safe to offer in-school education will influence when and by whom education programs will be delivered. Many schools and community-based organizations are adapting to an online or digital format.

While these efforts are being developed and implemented within a challenging environment, the COVID-19 pandemic is also an opportunity to ascertain how to improve upon course offerings, including ways to maximize interactions and tailor messages in an online environment. However, some school districts may not prioritize or have the resources and capacity to provide online sexual health education thus, potentially contributing to knowledge gaps. ${ }^{59}$ There are serious challenges about adopting online strategies without the necessary pedagogical refinements and support; such efforts are widely needed.

\section{Recommendation 4: Expand Access to Clinical Services Through Telehealth and Other Delivery Options}

Recognizing the variety of barriers that adolescents may encounter in accessing sexual health services in traditional clinic settings, policies, and programs should consider new service delivery models. Recently, several telehealth and other online platforms have been developed for adolescent sexual health services that have successfully addressed common barriers and concerns, including confidentiality and accessibility. ${ }^{60}$

Telehealth allows for two-way, live communication between a provider and a patient at a distant site, including audio and video equipment. In the era of COVID-19, it has provided an important strategy to decrease the number of potential patients exposed to the virus while ensuring ongoing provision of health care. A number of barriers have precluded its widespread adoption, including concerns about effectiveness, sufficient financial incentives, connectivity issues, and patient acceptability. ${ }^{61,62}$ As the body of evidence develops regarding the potential utility of telehealth, as well as when it is not appropriate to use, additional hybrid models will likely emerge.

The value added of assuring that adolescents are able to more easily access health care and that they may be more likely to seek care on a consistent basis may offset the additional resources needed in developing hybrid models of in-person clinic appointments with telehealth visits. Future research should consider the feasibility and effectiveness of other delivery models such as over-the-counter or pharmacist dispensing of oral contraceptive pills. Additional research will be necessary to ascertain what services best lend themselves to various health care delivery models and which are most appropriate for adolescents living in different settings and with varying levels of family support for accessing confidential care. It will also be important to assess whether adolescents have the necessary technological resources to be able to benefit from telehealth and other online platforms, as well as how to adapt delivery models to serve special populations, such as those who are homeless or living in crowded home situations, where confidentiality may not be feasible. ${ }^{63}$

\section{Recommendation 5: Design Programs and Services That Recognize and Address Structural Racism, Health Equity, and Inclusion}

While poverty, limited academic achievement, and family structure have been long associated with adolescent pregnancy, the contributions of structural and interpersonal racism have been fully considered as interventions have been developed and tested. In addition, the media has historically portrayed pregnant and parenting adolescents of color negatively. Racism has resulted in fewer highquality resources available in schools, limited economic opportunities for career development and advancement, lack of accumulated wealth, poorer quality housing, and worse physical and psychological environments for these adolescents. Policies that contributed to segregated schools, neighborhoods, and health care systems, as well as the racism experienced by youth of color and their families within health care systems, have also contributed to the high levels of distrust, avoidance, and fear in seeking care. Adolescents cite unfriendly interactions and distrust of providers as barriers for not seeking sexual health services. $^{41}$

Little progress has been made regarding changing the broader society's role and responsibility for the life options 
that many youth have available. Structural inequalities in opportunity and access to societal resources severely curtails the promise of adolescence for many youth now and throughout their lives. Adolescence needs to be recognized a period of extraordinary opportunity for learning and exploration, laying a strong foundation for a healthy and successful life, and reversing the worsening inequities of childhood disadvantage, thereby enabling all adolescents to flourish. ${ }^{64}$

Greater health equity will be achieved only when everyone has an equal opportunity to reach their health potential regardless of their race, ethnicity, religion, gender identity, sexual orientation, and disability. ${ }^{64}$ Such approaches will require the adoption of a socioecological perspective and systems thinking approach that recognizes the multiple systems and environments that must be aligned to truly support youth as they navigate their neighborhoods, schools, and health care systems. ${ }^{65-68}$ This perspective recognizes that adolescent sexual health outcomes and behaviors are contingent on myriad interrelated factors. ${ }^{68}$ The choices that adolescents make are influenced not only by their personal values and choices, but also their environment, including their peers, family, school, community, and a wide variety of policies. A socioecological perspective also requires addressing barriers across systems, as well as building on community strengths, assets, and partnerships.

Developing initiatives that take into account social determinants and adopt a lens of equity and racial justice requires the active involvement and reckoning of a number of different segments of society - from the individual and their family to schools, social services, housing, the business sector, the legal and judicial systems, to health care, and many others. These partners need to examine how centuries of policies have shaped the environments in which today's adolescents live. Efforts to correct longdamaging policies requires more than merely the provision of sexual health education and clinical services. These will need to be a key part of the next generation of strategies.

\section{Conclusion: Moving Forward}

This review reflects upon key strategies aimed at preventing adolescent pregnancy, as well as the hard-earned lessons learned through generations of efforts. The promise and vibrancy of adolescence represent an important resource that all can benefit from. Investments in health and well-being, education, and social support are key to assuring that all adolescents can maximize their full potential. Taking insights from the past, we can build on our history to shape strategies that acknowledge and enhance the strength, resilience, and centrality of our country's adolescents.

\section{Disclosure}

Dr. Brindis' time was partially supported by the Health Resources and Services Administration (HRSA) of the U. S. Department of Health and Human Services (under \# U45MC27709, Adolescent and Young Adult Health Capacity Building Program) and HRSA grant \# T71MC00003. This information or content and conclusions are those of the authors and should not be construed as the official position or policy of, nor should any endorsements be inferred by HRSA, Health and Human Services, or the U.S. Government. The sponsors had no role in the preparation or submission of this article. The authors report no other conflicts of interest for this work.

\section{References}

1. Gavin LE, Catalano RF, David-Ferdon C, Gloppen KM, Markham CM. A review of positive youth development programs that promote adolescent sexual and reproductive health. J Adolesc Health. 2010;46(3):S75-S91.

2. Martinez GM, Abma JC. Sexual Activity and Contraceptive Use Among Teenagers Aged 15-19 in the United States, 2015-2017. NCHS Data Brief. 2020;366:1-8.

3. Salam RA, Faqqah A, Sajjad N, et al. Improving adolescent sexual and reproductive health: A systematic review of potential interventions. J Adolesc Health. 2016;59(4):S11-S28. doi:10.1016/j. jadohealth.2016.05.022

4. Schroeder E, Kuriansky J. Sexuality Education: Past, Present, and Future [4 Volumes]. ABC-CLIO; 2009.

5. Brittain AW, Loyola Briceno AC, Pazol K, et al. Youth-Friendly Family Planning Services for Young People: A Systematic Review Update. Am J Prev Med. 2018;55(5):725-735. doi:10.1016/j. amepre.2018.06.010

6. Martin JA, Hamilton BE, Osterman MJK, Driscoll AK. Births: final Data for 2018. Natl Vital Stat Rep. 2019;68(13):1-47.

7. Centers for Disease Control and Prevention. CDC Winnable Battles: Final Report. Atlanta: Centers for Disease Control and Prevention; 2016.

8. Martinez GM, Abma JC. Sexual Activity, Contraceptive Use, and Childbearing of Teenagers Aged 15-19 in the United States. NCHS Data Brief. Number 209. Centers for Disease Control and Prevention; 2015.

9. Kann L, McManus T, Harris WA, et al. Youth risk behavior surveillance-United States, 2017. MMWR Surveillance Summaries. 2018;67(8):1. doi:10.15585/mmwr.ss6708a1

10. Boonstra HD. What Is Behind the Declines in Teen Pregnancy Rates? Guttmacher Policy Review. 2014;17(3):15.

11. Hamilton BE. State Teen Birth Rates by Race and Hispanic Origin: United States, 2017-2018. Hyattsville, MD; 2020.

12. Tyler KA, Whitbeck LB, Chen X, Johnson K. Sexual health of homeless youth: prevalence and correlates of sexually transmissible infections. Sex Health. 2007;4(1):57-61. doi:10.1071/SH06045

13. Carpenter SC, Clyman RB, Davidson AJ, Steiner JF. The association of foster care or kinship care with adolescent sexual behavior and first pregnancy. Pediatrics. 2001;108(3):E46. doi:10.1542/peds.108.3.e46 
14. Decker MJ, Isquick S, Tilley L, et al. Neighborhoods matter. A systematic review of neighborhood characteristics and adolescent reproductive health outcomes. Health Place. 2018;54:178-190. doi:10.1016/j.healthplace.2018.09.001

15. Akers AY, Muhammad MR, Corbie-Smith G. "When you got nothing to do, you do somebody": A community's perceptions of neighborhood effects on adolescent sexual behaviors. Soc Sci Med. 2011;72 (1):91-99. doi:10.1016/j.socscimed.2010.09.035

16. Atkins R, Sulik MJ, Hart D, Ayres C, Read N. The effects of school poverty on adolescents' sexual health knowledge. Res Nurs Health. 2012;35(3):231-241. doi:10.1002/nur.21471

17. Cavazos-Rehg PA, Krauss MJ, Spitznagel EL, Schootman M, Cottler LB, Bierut LJ. Substance use and the risk for sexual intercourse with and without a history of teenage pregnancy among adolescent females. J Stud Alcohol Drugs. 2011;72(2):194-198.

18. Sterling SP, Sadler LS, Sterling SP, Sadler LS. Contraceptive use among adolescent Latinas living in the United States: the impact of culture and acculturation. J Pediatr Health Care. 2009;23(1):19-28. doi:10.1016/j.pedhc.2008.02.004

19. Yarger J, Decker MJ, Campa MI, Brindis CD. Rural-urban differences in awareness and use of family planning services among adolescent women in California. $J$ Adolesc Health. 2017;60 (4):395-401. doi:10.1016/j.jadohealth.2016.10.016

20. Betancourt JR, Green AR, Carrillo JE, Ananeh-Firempong O. Defining cultural competence: a practical framework for addressing racial/ethnic disparities in health and health care. Public Health Rep. 2003;118(4):293-302. doi:10.1016/S0033-3549(04)50253-4

21. Roche KM, Vaquera E, White RM, Rivera MI. Impacts of immigration actions and news and the psychological distress of US Latino parents raising adolescents. $J$ Adolescent Health. 2018;62 (5):525-531. doi:10.1016/j.jadohealth.2018.01.004

22. Lara D, Decker MJ, Brindis CD. Exploring how residential mobility and migration influences teenage pregnancy in five rural communities in California: youth and adult perceptions. Cult Health Sex. 2016;1-16.

23. Maternowska C, Estrada F, Campero L, Herrera C, Brindis CD, Vostrejs MM. Gender, culture and reproductive decision-making among recent Mexican migrants in California. Cult Health Sex. 2010;12(1):29-43. doi:10.1080/13691050903108688

24. Manlove J, Terry E, Gitelson L, Papillo AR, Russell S. Explaining demographic trends in teenage fertility, 1980-1995. Fam Plann Perspect. 2000;32(4):166-175. doi:10.2307/2648233

25. Miller BC, Benson B, Galbraith KA. Family relationships and adolescent pregnancy risk: A research synthesis. Dev Rev. 2001;21 (1):1-38.

26. Kirby D, Laris BA. Effective Curriculum-Based Sex and STD/HIV Education Programs for Adolescents. Child Dev Perspect. 2009;3 (1):21-29. doi:10.1111/j.1750-8606.2008.00071.x

27. Cronin J, Heflin C, Price A. Teaching teens about sex: A fidelity assessment model for Making Proud Choices. Eval Program Plann. 2014;46:94-102. doi:10.1016/j.evalprogplan.2014.05.010

28. LaChausse RG. A clustered randomized controlled trial of the Positive Prevention PLUS adolescent pregnancy prevention program. Am J Public Health. 2016;106(S1):S91-S96. doi:10.2105/ AJPH.2016.303414

29. Allen JP, Philliber S, Herrling S, Kuperminc GP. Preventing teen pregnancy and academic failure: experimental evaluation of a developmentally based approach. Child Dev. 1997;68(4):729-742. doi:10.2307/1132122

30. Philliber S, Kaye JW, Herrling S, West E. Preventing pregnancy and improving health care access among teenagers: an evaluation of the Children's Aid Society-Carrera Program. Perspect Sex Reprod Health. 2002;34(5):244-251. doi:10.2307/3097823

31. Kirby D. Effective approaches to reducing adolescent unprotected sex, pregnancy, and childbearing. J Sex Res. 2002;39(1):51-57. doi:10.1080/00224490209552120
32. Goesling B, Lugo-Gil J, Lee J, Novak T. Updated Findings from the HHS Teen Pregnancy Prevention Evidence Review: April 2013 Through July 2014. Princeton, NJ: Mathematica Policy Research; 2015.

33. Office of Adolescent Health. Teen Pregnancy Prevention Resource Center: evidence-Based Programs. http://www.hhs.gov/ash/oah/oahinitiatives/teen_pregnancy/db/tpp-searchable.html. Accessed October 1, 2020. 2012

34. Arons A, Decker M, Yarger J, Malvin J, Brindis CD. Implementation in practice: adaptations to sexuality education curricula in California. J Sch Health. 2016;86(9):669-676. doi:10.1111/josh.12423

35. Decker MJ, Gutmann-Gonzalez A, Price M, Romero J, Sheoran B, Yarger J. Evaluating the effectiveness of an intervention integrating technology and in-person sexual health education for adolescents (In the Know): protocol for a cluster randomized controlled trial. JMIR Res Protoc. 2020;9(8):e18060. doi:10.2196/18060

36. Widman L, Nesi J, Kamke K, Choukas-Bradley S, Stewart JL. Technology-based interventions to reduce sexually transmitted infections and unintended pregnancy among youth. J Adolesc Health. 2018;62(6):651-660. doi:10.1016/j.jadohealth.2018.02.007

37. National Academies of Sciences E, and Medicine,. Promoting Positive Adolescent Health Behaviors and Outcomes: Thriving in the 21st Century. Washington, D.C.: The National Academies Press; 2020.

38. Philliber S. Evaluating teen pregnancy prevention programs: decades of evolving strategies and practices. Societies. 2015;5(3):631-645. doi:10.3390/soc5030631

39. Mwaria M, Chen C, Coppola N, Ingrid M, Phifer M. A culturally responsive approach to improving replication of a youth sexual health program. Health Promot Pract. 2016;17(6):781-792.

40. Romero L, Pazol K, Warner L, et al. Vital signs: trends in use of long-acting reversible contraception among teens aged 15-19 years seeking contraceptive services-United States, 2005-2013. MMWR Morb Mortal Wkly Rep. 2015;64(13):363-369.

41. Fuentes L, Ingerick M, Jones R, Adolescents' LL. young adults' reports of barriers to confidential health care and receipt of contraceptive services. J Adolesc Health. 2018;62(1):36-43. doi:10.1016/j. jadohealth.2017.10.011

42. Macapagal K, Bhatia R, Greene GJ. Differences in healthcare access, use, and experiences within a community sample of racially diverse lesbian, gay, bisexual, transgender, and questioning emerging adults. LGBT Health. 2016;3(6):434-442. doi:10.1089/lgbt.2015.0124

43. Marcell AV, Morgan AR, Sanders R, et al. The socioecology of sexual and reproductive health care use among young urban minority males. J Adolescent Health. 2017;1-9.

44. Brindis CD, Geierstanger SP, Wilcox N, McCarter V, Hubbard A. Evaluation of a peer provider reproductive health service model for adolescents. Perspect Sex Repro H. 2005;37(2):85-91. doi:10.1363/ 3708505

45. World Health Organization. Quality Assessment Guidebook: A Guide to Assessing Health Services for Adolescent Clients. Geneva: World Health Organization; 2009.

46. Mazur A, Brindis CD, Decker MJ. Assessing youth-friendly sexual and reproductive health services: a systematic review. BMC Health Serv Res. 2018;18(1):216. doi:10.1186/s12913-018-2982-4

47. Soleimanpour S, Geierstanger SP, Kaller S, McCarter V, Brindis CD. The role of school health centers in health care access and client outcomes. Am J Public Health. 2010;100(9):1597-1603. doi:10.2105/ AJPH.2009.186833

48. Comfort AB, Rao L, Goodman S, et al. Improving capacity at school-based health centers to offer adolescents counseling and access to comprehensive contraceptive services. J Pediatr Adolesc Gynecol. 2020. doi:10.1016/j.jpag.2020.07.010

49. Upadhya KK, Santelli JS, Raine-Bennett TR, Kottke MJ, Grossman D. Over-the-counter access to oral contraceptives for adolescents. J Adolesc Health. 2017;60(6):634-640. doi:10.1016/j. jadohealth.2016.12.024 
50. Pandia Health. https://www.pandiahealth.com/. Accessed October 1, 2020. 2020

51. Barney A, Buckelew S, Mesheriakova V, The R-FM. COVID-19 pandemic and rapid implementation of adolescent and young adult telemedicine: challenges and opportunities for innovation. $J$ Adolescent Health. 2020;67(2):164-171. doi:10.1016/j.jadohealth.2020.05.006

52. Sobel L, Salfanicoff A, Frederiksen B. Title $X$ Regulations: Implications for Women and Family Planning Providers. Kaiser Family Foundation; 2019.

53. Flanigan C. What's Behind the Good News: The Decline in Teen Pregnancy Rates During the 1990s. National Campaign to Prevent Teen Pregnancy; 2001:1586710230.

54. Wertheimer RF, Jager J, Moore KA, Trends C. State Policy Initiatives for Reducing Teen and Adult Nonmarital Childbearing: Family Planning to Family Caps. Urban Institute; 2000.

55. Brindis C. Adolescent Pregnancy and Parenting in California: A Strategic Plan for Action. Center for Population and Reproductive Health Policy, Institute for Health Policy Studies: University of California, San Francisco; 1988.

56. Chervin DD, Philliber S, Brindis CD, et al. Community capacity building in CDC's Community Coalition Partnership Programs for the Prevention of Teen Pregnancy. J Adolesc Health. 2005;37(3 Suppl):S11-19. doi:10.1016/j.jadohealth.2005.06.001

57. Kramer JS, Philliber S, Brindis CD, et al. Coalition models: lessons learned from the CDC's Community Coalition Partnership Programs for the Prevention of Teen Pregnancy. J Adolesc Health. 2005;37(3 Suppl):S20-S30. doi:10.1016/j.jadohealth.2005.05.010

58. Loomis A, Simpson-Brown R. A Blueprint for Comprehensive School Based Pregnancy Prevention. California Department of Education; 1990.

59. Lindberg LD, Bell DL, Kantor LM. The Sexual and Reproductive Health of Adolescents and Young Adults During the COVID-19 Pandemic. Perspect Sex Reprod Health; 2020.
60. Williams RL, Meredith AH, Ott MA. Expanding adolescent access to hormonal contraception: an update on over-the-counter, pharmacist prescribing, and web-based telehealth approaches. Curr Opin Obstet Gynecol. 2018;30(6):458-464.

61. Cain S, Sharp S. Telepharmacotherapy for child and adolescent psychiatric patients. J Child Adolesc Psychopharmacol. 2016;26 (3):221-228. doi:10.1089/cap.2015.0039

62. Weinstein RS, Krupinski EA, Doarn CR. Clinical examination component of telemedicine, telehealth, mHealth, and connected health medical practices. Med Clin North Am. 2018;102(3):533-544. doi:10.1016/j.mcna.2018.01.002

63. Barney A, Buckelew S, Mesheriakova V, The R-FM. COVID-19 pandemic and rapid implementation of adolescent and young adult telemedicine: challenges and opportunities for innovation. $J$ Adolesc Health. 2020;67(2):164-171.

64. National Academies of Sciences Engineering Medicine. The Promise of Adolescence: Realizing Opportunity for All Youth. National Academies Press; 2019.

65. Bronfenbrenner U. The Ecology of Human Development: Experiments by Nature and Design. Cambridge, MA: Harvard University Press; 1979.

66. Leischow SJ, Best A, Trochim WM, et al. Systems thinking to improve the public's health. Am J Prev Med. 2008;35(2 Suppl): S196-S203. doi:10.1016/j.amepre.2008.05.014

67. Diez Roux AV, Mair C. Neighborhoods and health. Ann N Y Acad Sci. 2010;1186:125-145

68. Grzywacz JG, Fuqua J. The social ecology of health: leverage points and linkages. Behav Med. 2000;26(3):101-115.
Adolescent Health, Medicine and Therapeutics

\section{Publish your work in this journal}

Adolescent Health, Medicine and Therapeutics is an international, peer-reviewed, open access journal focusing on health, pathology, and treatment issues specific to the adolescent age group. All aspects of health maintenance, preventative measures and disease treatmen interventions are addressed within the journal and practitioners from all disciplines are invited to submit their work as well as healthcare researchers and patient support groups. The manuscript management system is completely online and includes a very quick and fair peerreview system. Visit http://www.dovepress.com/testimonials.php to read real quotes from published authors. 